\title{
Merit 2.0: Implications of the 2003 Public Service Employment Act on Merit as an Organizing Principle in the Federal Public Service
}

\begin{abstract}
This paper investigates the first ever statutory definition of merit in the 2003 Public Service Employment Act. The assertion of the paper is that although it has yet to materialize, the statutory definition has created an opportunity to water down the merit system and compromise the integrity of meritorious appointments. To provide background for the evaluation and contextualize the 2003 change, a brief history of the merit system as operationalized in Canada's Public Service and a discussion of competing conceptualizations of merit is included.
\end{abstract}

\begin{abstract}
About the Author(s): Brett W. Taylor is pursuing a combined Master of Public Administration and Law (JD-MPA) degree at Dalhousie University. Prior to this he earned a BA and MA in history at McMaster University. His article on the public service employment act was originally written for a first year human resources course in the MPA program. Though he grew up in Beamsville Ontario, Brett also lived in Hamilton, Ottawa, Winnipeg, and Vienna before settling outside of Halifax in beautiful Shad Bay.
\end{abstract}




\section{Introduction}

On November $7^{\text {th }}$, 2003 the new Public Service Employment Act (PSEA) received Royal Assent. The Act not only made significant changes to the Public Service Commission's (PSC) role in human resource management for the Federal Public Service, but also legislated a definition of merit for the first time. In that same year the Honourable Lucienne Robillard, then President of the Treasury Board, claimed that "as a public institution, the public service is not, and cannot be managed in the same way as a business... it is, and must be, subject to greater scrutiny in its hiring and management practices" (Barrados and Hill, 2009). What this paper seeks to explore is whether the recently legislated definition of merit has served to increase scrutiny above the level of private business - or if instead it has brought public service practices more in line with those of business. In essence, has the definition served to strengthen or weaken the merit principle within the Canadian Public Service?

This paper will argue that while results are to date inconclusive, the 2003 definition has created an opportunity for the weakening of the merit principle in the Canadian Public Service. This will be argued both by analyzing the PSEA definition and its potential implications and by examining evaluations of its actual effects on public service staffing. First, however, some background will be provided. In order to effectively investigate merit we must first understand its meaning. Additionally, in order to understand the 2003 PSEA we need to appreciate the circumstances that led to its creation. As such, this paper will begin with a discussion of the concept of merit and its various definitions and interpretations. It will then examine the forces that led to the 2003 PSEA and contributed to its form. Finally, the 2003 PSEA definition of merit and meritorious appointments will be scrutinized, along with a discussion of potential and realized implications.

\section{Defining Merit}

Ken Kernaghan (2011) argued that merit has historically been poorly defined and "getting all of the major players to agree on the concept's proper meaning and application is a formidable task" (p. 4). Luc Juillet and Ken Rasmussen (2008) have likewise argued "the exact meaning and practical implications of this idea have often been ill defined and the object of much controversy" (p. 6). As such, this paper will begin by explaining some key distinctions in conceptualizing merit. 


\section{Merit Principle versus Merit System}

There is a fundamental distinction between the merit principle and the merit system. As Kernaghan (2008) has noted, the intention of the 1918 Civil Service Act was to make the key determinant in public service staffing the "merit principle". What resulted, however, was "a collection of rules, regulations, policies and procedures peculiar to the Canadian civil service which have been designed to implement the principle" (Kernaghan, 2008, para. 7). Hodgetts et al. (1972) likewise observed that the 1918 Act did not provide any definition of merit. Instead its meaning was taken for granted and only the mechanics of the merit system were legislated (Hodgetts et al., 1972, p. 52).

What exists then are two distinct conceptualizations of merit: the merit principle whereby appointments are made on the basis of qualifications for the position and candidates are selected in a manner that precludes patronage and ensures political neutrality, and the merit system, the body of rules and regulations that serves to ensure this end.

Further, it is important to note the two conceptualizations are not of necessity congruent. The merit system has incorporated other goals such as representativeness and equality of opportunity that can be at odds with the merit principle as defined above. Kernaghan (2008) notes that though the aim of the PSC was to promote the merit principle what resulted was "an instrumental type of merit in the form of a system of structures and procedures that departs substantially from the ideal" (para. 21).

\section{Relative Merit versus Individual Merit}

Like the difference between the merit system and principle, there is an equally important distinction between relative and individual merit. In describing the merit system created in 1918, J.D. Love (1988) noted that not only were candidates required to be qualified and appointed in a non-partisan and competitive manner, but also that lists of eligible candidates were ranked and appointments were made according to that ranking. What Love describes is relative opposed to individual merit. Relative merit refers to a candidate's qualifications or suitability in comparison to other candidates. Individual merit, on the other hand, is a candidate's ability to meet stated requirements of a position.

Both individual and relative merit have been utilized in Canadian public service appointment processes historically, and cross jurisdictionally. When writing in 1988 , Love noted that Nova Scotia ranked candidates comparatively before selection. 
Peter Aucoin and Elizabeth Goodyear-Grant (2002), writing on appointments to agencies, boards, and commissions in Nova Scotia, argued that relative merit ranking was superior to individual merit in safeguarding the selection process from patronage and ensuring accountability. A weakness of individual merit is that many candidates may be qualified for a position, allowing selection to be based on other factors. This could open the door for either political or bureaucratic patronage.

Aucoin and Goodyear-Grant (2002) argued that the weakness of individual merit qualification requirements is exacerbated in situations where job qualifications are inherently difficult to create or where inadequate processes are poorly defined prior to candidate evaluation. They also claimed that since a "merit-based regime is meant to appoint the best candidate for each position" picking from amongst individually qualified candidates once relative merit has been established is counterproductive to achieving the basic goal of merit based appointment (p. 314). As will be seen below, the tendency within Canada's Federal Public Service has been to use relative merit instead of individual merit - though not always at the pleasure of either the PSC or public service managers.

\section{A History of Merit in Canada's Public Service}

This paper does not purport to provide a comprehensive history of merit and the Public Service Commission. Other writers, particularly Kenneth Kernaghan (2008), have covered that thoroughly (see also Juillet and Rasmussen, 2008; Hodgetts et al., 1972). Rather, the following section outlines historical factors that led to the 2003 changes to the PSEA and a more general reorganization of the federal Human Resource Management structure.

Since 1918 both the merit system and merit principle have been constantly evolving. Evolution, however, has often progressed in ways that the PSC, parliament, public service managers, or the public, have deemed ineffective. Juillet and Rasmussen (2008) noted that as the bureaucracy grew through the postwar years and the commission attempted "to make the principle of merit an operational reality" ( $p$. 4 ), the rules became more complex and cumbersome. Management was stifled, efficiency was compromised, the public service became "a poster child for bureaucratic inefficiency", and some were of the mind there was "no merit in the merit system" (Juillet and Rasmussen, 2008, p. 4). The 1961 Glassco report wrote:

[ $t$ ] he merit system, in many of its current practices, frustrates the attainment of the principle; in its name many absurd procedures are 
tolerated; the system has become an end in itself; overriding the need to 'get the job done'; and all too frequently it has engendered such delays in the attempt to get the "best" man that his loss to a more nimble employer was ensured (in Kernaghan, 2008, para. 50).

In short, the merit system had its flaws and was frequently reorganized in an effort to address them.

Not all readjustments, however, were in response to operational concerns. Juillet and Rasmussen (2008) note that historically merit has acted as "an uneasy proxy for different sets of values and aspirations that are themselves not easy to either define or reconcile" (p. 7). They argue that merit is not merely about qualifications, but also about societal values and ethics. The advent of bilingualism and multiculturalism presented challenges to the system and forced the public service to reconsider its conceptualization of merit to include linguistic and representational factors. The 2003 changes were, like prior readjustments, intended to address shifting societal values and were in response to calls for greater operational flexibility and increased efficiency.

\section{Operational Flexibility}

Prior to 2003, merit was never defined. Rather, it was brought to life through regulation and procedure. Juillet and Rasmussen (2008) argue that despite never being defined by parliament or the PSC, merit was defined in practice by the courts. Over time, as staffing decisions were challenged in court, a working definition was formed which emphasized relative over individual merit (Juillet and Rasmussen, 2008, 213). In 1992 the PSEA was amended to increase use of individual merit but this remained ineffective through to the 2003 changes as procedures remained cumbersome and candidates were rigorously ranked to prevent grounds for appeal.

Juillet and Rasmussen (2008) argue that the 2003 definition was meant to move selection procedures away from this approach and counter the court imposed definition. Juillet (2011) argues elsewhere that the definition was not a break from previous policy, but rather in line with earlier attempts to promote less prescriptive approaches to staffing, allow increased flexibility, and promote values based decision making. Use of the court imposed relative merit approach made values based staffing decisions difficult to make without becoming vulnerable to appeal. 


\section{Values Based Staffing}

As noted above, inclusion of values into the conceptualization of merit was necessitated by the advent of linguistic and regional representativeness concerns. It remained so throughout the 1990s. An excerpt from the 1995 Treasury Board Managers' Deskbook is worth quoting at length to illustrate this point:

[a]ppointments to the Public Service are based on merit, and Public Service employees advance in accordance with merit. This means that the knowledge, experience, abilities and personal suitabilities of candidates are evaluated against the requirements of the position. It also means that the best qualified person (relative merit) or a qualified person based on a standard of competence (individual merit) is selected, and that treatment of Public Service employees and those seeking employment in the Public Service is fair and equitable. The Public Service must be highly competent, totally professional and politically neutral in providing advice to the government and quality services to the Canadian public. It also must be representative of the population it serves. Its staffing system must be easy to manage, economical to operate and sufficiently flexible to meet changing operational needs and driven by ... values (fairness, equity and transparency)... (Treasury Board of Canada, 1995, p. 3.1-1)

What is particularly notable is the inclusion of both relative and individual merit, with no mention of potential conflict between the two, particularly with respect to representativeness. Given the court's preference for relative merit it would be difficult for a manager to give much credence to values based staffing. Despite 1992 amendments to the PSEA intended to promote individual merit values based decision making remained incompatible with the merit system.

\section{The 2003 Public Service Employment Act}

The 2003 PSEA was specifically designed to allow increased operational freedom and promote values based decision making. Key to achieving these goals was to define merit. Juillet and Rasmussen (2008) have written "the definition of merit was modified in the pursuit of greater managerial efficiency" (p. 185). Kernaghan (2008) writes: "The PSEA not only provided legislative definition of merit; it also provided 
a definition that departed considerably from the traditional one" (para. 81). As will be discussed below, both assessments are correct.

According to the PSEA, a meritorious appointment is one where "the person to be appointed meets the essential qualifications for the work to be performed, as established by the deputy head, including official language proficiency" (Canada, 2003, s. 30). In addition to this basic requirement, however, the following may also be considered:

(i) any additional qualifications that the deputy head may consider to be an asset for the work to be performed, or for the organization, currently or in the future,

(ii) any current or future operational requirements of the organization that may be identified by the deputy head, and

(iii) any current or future needs of the organization that may be identified

by the deputy head. (Canada, 2003, s. 30)

Additionally, the same section states that consideration of more than one applicant is not required.

The definition of merit is thus both more restrictive and more expansive than previous interpretations. It is more restrictive in that merit consists only of one's qualifications in relation to the work - individual merit. It is at the same time more expansive in that beyond essential job requirements, managers are now permitted to consider an array of other qualifications that, while not essential to the position, would be deemed an asset. There is no mention of ranking and relative merit is conspicuously absent.

The 2003 definition represents a seismic shift - a system formerly dominated by relative merit has been redesigned to consider individual merit almost exclusively. This shift has obvious implications for increasing flexibility, particularly when paired with the inclusion of non-essential assets as a factor for consideration. Flexibility is not restricted to pursuing operational needs, but could also be used to promote values based hiring, so long as candidates meet required qualifications. The effects of this change, both possible and realized, are examined next.

\section{Possible Effects}


When the changes were first introduced, there was criticism of the watering down of merit in the PSEA. Nycole Turmel, then president of the Public Service Alliance of Canada, claimed that the bill:

in its current form, represents a wholesale retreat from a public service defined by the appointment of the best-qualified individuals... the PSAC fears that the new PSEA has the potential to usher in a new era of patronage, favoritism and a lack of accountability that is inconsistent with the government's stated objective. (Juillet and Rasmussen, 2008, p. 215)

Canadian Alliance MP Paul Forseth similarly stated his objections:

My problem is that the new, watered down definition of merit gives no direction to select the best person for the job within a specific competition process. Since that basic goal would no longer be required, no justification or accountability would be required to defend perhaps a sloppy selection process or even insider advantage to a favoured person... There is nothing that will bring the whole system down faster. (Juillet and Rasmussed, 2008, p. 214)

These allegations are not without basis. The new merit system created by the 2003 PSEA does dramatically change the measures of accountability within the system. Without rankings how is one to appeal?

While this cost, or risk, is one that the PSC has calculated to be outweighed by gains in operational efficiency, we must nonetheless be vigilant and recognize the avenues now open for patronage. While hiring remains far removed from political actors, and so political patronage seems unlikely, there are fewer protections than provided by relative merit. Furthermore, opportunities for bureaucratic patronage patronage based not on political allegiance but on relationships within the bureaucracy - are greatly increased. It is too early to conclude that merit has indeed been watered down, but the 2003 PSEA has certainly opened the door to this possibility.

On a more theoretical note, one certain effect of definition is an end to eighty five years of amorphous 'living' definitions created not by legislation but by the merit system itself. Writing with Ned Franks, Ted Hogetts claimed that merit was "an ideal in constant need of redefinition in light of changing circumstances and perceptions" (in Barrados and Hill, 2009, para. 31). Definition and redefinition were part of an ongoing 
dialogue between those promoting the idea and those applying it; merit was "a living, breathing concept" (Barrados and Hill, 2009, para. 32). For better or worse, the 2003 PSEA has taken life and breath away from this concept.

\section{Recorded Effects}

While it is too early to make definitive conclusions regarding the consequences of the 2003 PSEA, particularly given that it came into effect only in 2005, some early observations have been made. Juillet (2011) notes that within the first few years of operation, it has become clear that many managers and executives believe they are required only to conform "with the minimal legal requirements spelled out in the Act, especially the narrower definition of meritorious appointment" (p. 24). He recommends the creation of more detailed staffing policies to address this and aid the implementation of the PSEA (Juillet, 2011 , p. 9).

Another review by Maria Barrados and Margaret M. Hill (2009) found that while individual hiring decisions seemed appropriate, the new definition of merit "requires at both the individual and system levels - a more sophisticated approach to applying the core and guiding values and weighting the values in different circumstances" (para. 35). It was further noted that the definitional change may necessitate reappraisal of how performance, both of individual hiring managers and of the human resource management system as a whole, is measured (Barrados and Hill, 2009). It was also reported that though many of the changes in the PSEA were designed to promote efficiency, hiring time had actually increased since it came into force.

A final note on realized effects is that regardless of whether or not the revamped merit system has watered down the merit principle, employees believe that it has. A 2008-09 survey indicated that

$24 \%$ of respondents in organizations falling under the PSEA who provided an opinion did not agree that in their work unit they "hire people who can do the job"; and 35\% did not agree that when they were a candidate in competitions during the previous three years "competitions were run in a fair manner." (Barrados and Hill, 2009, para. 39)

Actual effects aside, public service employees believe the 2003 PSEA had a negative effect on employment practices.

\section{Conclusions}


The 2003 PSEA represents a significant shift in the ever evolving history of the merit system in Canada. Despite this shift though, the merit system is not going anywhere. A 2007 report to the Prime Minister noted that "the first premise for our work as a committee is that a well-functioning and values based public service is critical to the success of every country... a high-quality, merit-based Public Service is part of Canada's comparative advantage" (Mazankowski et al., 2007, para. 17).

The question this paper seeks to answer is whether the change in the merit system is significant enough to fundamentally alter what we conceptualize the merit principle to embody. Given the change, does Lucienne Robillard's claim that "the public service is not, and cannot be managed in the same way as a business" still ring true? Has the merit principle been watered down?

The contention of this paper is that it has not, not yet at least. The shift from relative merit to individual merit has not to date significantly altered the functioning of the merit principle within the merit system. That said, the shift has created the possibility for that to happen. In essence, the 2003 definition of merit has opened the door for a watering down of merit, but we have yet to cross the threshold. It is the hope of this author that through careful management - instituting more detailed staffing policies as recommended by Luc Juillet and adjusting performance measurement as suggested by Barrados and Hill - such an outcome is avoided 


\section{References}

Aucoin, P. \& Goodyear-Grant, E. (2002). Designing a merit-based process for appointing boards of $A B C s$ : Lessons from the Nova Scotia reform experience. Canadian Public Administration 45(3), 301-327.

Barrados, M., \& Hill, M. (2009) "A paper presented at the Hodgetts legacy: Towards the future" Queen's University, Kingston, ON, October 23. Retrieved from http://www.psc-cfp.gc.ca/abt-aps/rprt/hodgetts/index-eng.htm

Canada. (2003). Public Service Employment Act, S.C. 2003, c. 22, ss. 12, 13. Retrieved from http://laws-lois.justice.gc.ca/PDF/P-33.01.pdf

Hodgetts, J.E., McCloskey, W., Whitaker, R., \& Wilson, V. (1972). The biography of an institution: The civil service commission of Canada, 1908-1967. Montreal and London: McGill-Queen's University Press.

Juillet, L. (2011). The public service commission and the implementation of the Public Service Employment Act (2003). Ottawa: Public Service Commission of Canada. Retrieved from http://www.psc-cfp.gc.ca/abtaps/rprt/juillet/docs/juillet-eng.pdf

Juillet, L., \& Rasmussen, K.. (2008). Defending a contested ideal: Merit and the PSC of Canada 1908-2008. Ottawa, ON: University of Ottawa Press.

Kernaghan, K.. (2008). A literature review on the evolution of the concept of merit in public service: Canadian and comparative perspectives. Ottawa, ON: Public Service Commission of Canada. Retrieved from http://www.psccfp.gc.ca/abt-aps/rprt//recmps-rlecmfp/index-eng.htm

Kernaghan, K. (2011). Getting engaged: Public-service merit and motivation revisited. Canadian Public Administration, 54(14), 1-21.

Love, J.D. (1988). The merit principle in the provincial governments of Atlantic Canada. Canadian Public Administration, 31 (1), 335-351.

Mazankowski, D., Tellier, P., Lacroix, R., Landry, A., D'Alessandro, D., Stymiest, B., Wilson, L. (2007). Report to the Prime Minister, March 2007. Ottawa, ON: Treasury 
Board Secretariat. Retrieved from http://www.tbs-http://www.tbssct.gc.ca/ren/cpmc/cpmcl-eng.asp

Treasury Board of Canada. (1995). The managers' deskbook, $4^{\text {th }}$ ed. Ottawa, ON: Minister of Supply and Services. 